\title{
MODELLING AND SIMULATION OF FRESH-PRODUCT SUPPLY CHAIN CONSIDERING RANDOM CIRCULATION LOSSES
}

\author{
Fang, X..$^{* * *}$; Wang, R. ${ }^{* *}$; Yuan, F. J.**; Gong, Y.,**\#; Cai, J. R. ${ }^{* *} \&$ Wang, Y. L. ${ }^{* *}$ \\ ${ }^{*}$ Chongqing Engineering Research Centre for Processing, Storage and Transportation of Characterized \\ Agro-products, Chongqing 400067, P. R. China \\ ${ }^{* *}$ School of Planning, Chongqing Technology and Business University, Chongqing 400067, \\ P. R. China \\ E-Mail: cqgongying@ ctbu.edu.cn ( ${ }^{\#}$ Corresponding author)
}

\begin{abstract}
Random circulation losses of fresh products are also a great challenge that affects the decision-making of farmers and enterprises as well as the revenue management of both parties. Considering a freshproduct supply chain (FSC) comprising a single enterprise and a single farmer with random circulation losses, we explore the optimal ordering of the enterprise, optimal planting of the farmer, and risksharing mechanism of both participants. After modelling the optimal decision model of centralized FSC, we solve the optimal global solutions that exist uniquely. Then, a risk-sharing contract, called a wholesale price contract, is designed that can coordinate the decentralized FSC. Finally, a simulation of sensitivity analysis using MATLAB soft is figured out to explore the influence of random risks on the optimal solutions and the contract parameters. Furthermore, some conclusions and future researches are given.

(Received in October 2019, accepted in February 2020. This paper was with the authors 1 month for 2 revisions.)
\end{abstract}

Key Words: Fresh Product, Circulation Loss, Wholesale Price, Supply Chain

\section{INTRODUCTION}

With the strengthening of agriculture supply-side reform, the trading quantity of fresh products is steadily increasing. It is predicted that the volume of trading will reach CNY 2.31 billion by 2020 , and the compound annual growth rate will reach $14.16 \%$. However, there exist several circulation losses of fresh products during the transportation, special packing procedures, environmental risk and so on $[1,2]$, such as the quality deterioration and the physical quantity deterioration [3]. It is about 20\%-30\% that all fresh products are wasted in whole FSC system [4], and the circulation loss of fruits and vegetables is about $15 \%-30 \%$ of the total world production [5]. The circulation loss of fresh products is not only a significant obstacle to improve the performance of FSC but also a severe problem faced by FSC management.

Contrasting to the random yield, the circulation loss of fresh produce items usually occurs after a farmer delivers products. Generally, the circulation loss of them can be managed by applying the preservation-technology activities [1, 6-11], improving warehouse and transportation processes $[12,13]$ or using risk-sharing contracts [14-23]. The investment in such activities can reduce circulation loss rate and consequently can increase the available quantity of fresh produce items, and the coordination in such contracts can enhance the performance of the FSC system and its parties. Although investment in preservationtechnology activities reduces the circulation loss rates of fresh produce items, it cannot eliminate the circulation loss of them. For any given technology level, the circulation loss will still exist for fresh produce items. Therefore, the circulation loss is an inherent attribute of FSC, and enterprises (especially those in traditional channels) need to consider the influence of the circulation loss rate on their ordering or planting decisions. 
In this paper, we consider a two-echelon FSC with a single "enterprise + farmer" and assume that the circulation loss of fresh produce items is an exogenous parameter and explore the following two problems. How many the enterprise should order, and how much the farmer should plant fresh products? And how should random risks be shared between the enterprise and the farmer? The process of the game is as follows. The enterprise orders fresh products from the farmer and sales them in the market. Constrained by the current technology level, the farmer's output of fresh products and the circulation loss of fresh products are random variables. First, the optimal decision-making in the FSC is investigated by using mathematical modelling. Then, a flexibly coordinated wholesale price contract mechanism is designed to encourage the enterprise and farmer to share the random risks. Finally, a sensitivity analysis of random risks is carried out through the MATLAB soft simulation to explore the influence of random risks on the optimal solutions and contract parameters, and some conclusions are discussed.

\section{MODELLING OF THE FSC}

In this section, the optimal solutions and optimal profit of a centralized FSC are deduced, and then the coordinated contract mechanism is designed to encourage both parties to share random risks.

\subsection{Model description}

A two-echelon FSC with two participants called enterprise $\mathrm{E}$ and farmer $\mathrm{F}$ is considered, in which the enterprise is the leader and the farmer is the follower. The game sequence is as follows: the enterprise orders $q$ units of the fresh produce from the farmer; then, the farmer plans to grow $Q$ units of the fresh produce based on the orders of the enterprise. The market demand $X$, the yield of the fresh produces $U$, and the circulation loss of the fresh products $O$ are all viewed as random variables. The game timing of both parties is shown in Fig. 1, and the notation used in this paper is shown in Table I.

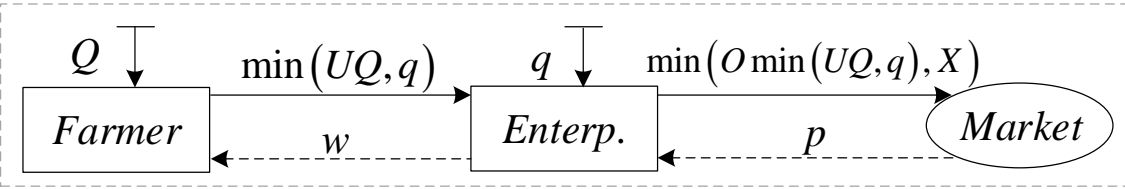

Figure 1: Schematic diagram of a fresh produce supply chain under circulation loss.

Table I: Notations.

\begin{tabular}{|c|l|}
\hline Notation & Description \\
\hline$U$ & Plant yield of the fresh products; this is a random variable \\
\hline$G(u)$ & The cumulative distribution function of random variable $U$ \\
\hline$g(u)$ & The probability density function of random variable $U$ \\
\hline$O$ & Fresh circulation output rate; this is a random variable \\
\hline$M(o)$ & The cumulative distribution function of random variable $O$ \\
\hline$m(o)$ & The probability density function of random variable $O$ \\
\hline$X$ & Market demand for fresh products; this is a random variable \\
\hline$F(x)$ & The cumulative distribution function of random variable $X$ \\
\hline$f(x)$ & The probability density function of random variable $X$ \\
\hline$q$ & Quantity the enterprise plans to order; this is a decision variable \\
\hline$Q$ & The amount the farmer plans to plant; this is a decision variable \\
\hline$w$ & Per unit wholesale price of the fresh products; this is a contract parameter \\
\hline$p$ & The market price of fresh products \\
\hline$c_{E}$ & Per-unit circulation loss cost of the fresh produces \\
\hline$C_{F}$ & Per-unit planting cost of the fresh produces \\
\hline
\end{tabular}




\subsection{Optimal solutions and coordination of the FSC}

The optimal solutions include the optimal amount the farmer should plant, the optimal amount the enterprise should order and the optimal expected profit of the globally FSC. The expected profit function of the centralized FSC is as follows:

$$
\Pi_{C}=p E[\min (\operatorname{Omin}(U Q, q), X)]-c_{E} E[\min (U Q, q)]-c_{F} Q
$$

Proposition 1. The optimal values $\left(Q_{C}^{*}, q_{C}^{*}\right)$ that can maximize $\Pi_{C}$ exist and unique, which satisfy:

$$
\left\{\begin{array}{c}
\int_{0}^{1} \bar{M}(o) \bar{F}\left(o q_{C}^{*}\right)\left[1-\Upsilon\left(o q_{C}^{*}\right)\right] d o=c_{E} / p \\
\int_{0}^{q_{C}^{*} / Q_{C}^{*}} \int_{0}^{1} u g(u) \bar{M}(o) \bar{F}\left(o u Q_{C}^{*}\right)\left[1-\Upsilon\left(o u Q_{C}^{*}\right)\right] d o d u-\frac{c_{E}}{p} \int_{0}^{q_{C}^{*} / Q_{C}^{*}} u g(u) d u=\frac{c_{F}}{p}
\end{array}\right.
$$

Substitution $\left(Q_{C}^{*}, q_{C}^{*}\right)$ into Eq. (1), the integrated optimal expected profit of the centralized FSC which is regarded as $\Pi_{C}^{*}$, can be obtained.

In the decentralized FSC, the expected profit functions of the enterprise and the farmer are as follows:

$$
\begin{gathered}
\pi_{E}=\left[p \int_{0}^{q / Q} \int_{0}^{1} \bar{M}(o)[\bar{G}(q / Q) \bar{F}(o q)+u g(u) \bar{F}(o u Q)] d o d u-\left(w+c_{E}\right) \int_{0}^{q / Q} \bar{G}(u) d u\right] Q \\
\pi_{F}=\left[w \int_{0}^{q / Q} \bar{G}(u) d u-c_{F}\right] Q
\end{gathered}
$$

To seize the optimal expected profit $\Pi_{C}^{*}$, the parties need to voluntarily share the risk stemming from the randomness of the variables with a given wholesale price contract. The wholesale price is the only parameter connecting the enterprise and the farmer according to compare to Eqs. (3) and (4). Therefore, the wholesale price is designed as shown in Proposition 2.

Proposition 2. The per-unit wholesale price $w$ of the agricultural products is:

$$
w=\delta c_{F} / \theta^{*}+(1-\delta)\left(p \Theta^{*}-c_{E}\right)
$$

where $\delta \in(0,1), \theta^{*}=\int_{0}^{q_{C}^{*} / Q_{C}^{*}} \bar{G}(u) d u$, and $\Theta^{*}=\frac{\int_{0}^{q_{C}^{*}} / Q_{C}^{*} \int_{0}^{1} \bar{M}(o)\left[\bar{G}\left(q_{C}^{*} / Q_{C}^{*}\right) \bar{F}\left(o q_{C}^{*}\right)+u g(u) \bar{F}\left(\text { ou } Q_{C}^{*}\right)\right] \operatorname{dod} u}{\theta^{*}}$.

The wholesale price contract determined by Eq. (5) can coordinate the decentralized FSC. At this time, the expected profit of the enterprise and the farmer is as $\pi_{E}=\delta \Pi_{C}^{*}$ and $\pi_{F}=(1-\delta) \Pi_{C}^{*}$, respectively.

\section{SIMULATION OF THE FSC}

The simulation sensitivity analysis is divided into two steps; the first step is a benchmark analysis for global optimization solutions, and the second step is sensitivity analysis for three risks.

\subsection{Benchmark analysis}

It is assumed that an enterprise processes wolfberry as raw material for medicinal wine and assumed that $X \sim N\left(\mu_{X}, \sigma_{X}^{2}\right), U \sim N\left(\mu_{U}, \sigma_{U}^{2}\right)$, and $O \sim N\left(\mu_{O}, \sigma_{O}^{2}\right)$, respectively. In addition, we assume that $\mu_{X}=50, \sigma_{X}=5, \mu_{U}=0.7, \sigma_{U}=0.2, \mu_{O}=0.8$, and $\sigma_{O}=0.1$. The unit planting cost of the farmer $c_{F}$ equals 5 , and the unit circulation loss cost of enterprise $c_{E}$ equals 3 . The market price of the processed products $p$ equals 20 . The opportunity cost of the enterprise and the farmer are zero, and the accuracy of the numerical simulation is set at four decimal places. The results of the simulation are shown in Table II.

The simulation results in Table II show that (1) because the planting output, circulation loss and market demand of wolfberry are random, the farmer plants $6.09 \%$ more than the enterprise orders. (2) The expected order quantity of the enterprise (i.e. the expected transaction quantity of wolfberry) is $Q_{C}^{*} \theta^{*}=52.0593$, which is $69.05 \%$ of the farmers' 
planting quantity, and the expected sales volume of the enterprise is $Q_{C}^{*} \theta^{*} \Theta^{*}=39.4870$, which is $52.37 \%$ of the farmers' planting amount. These data show that uncertainty from the initial planting of wolfberry to the final market results in nearly half of the losses. (3) When the perunit wholesale price of wolfberry is 7.2410 , the enterprise obtains all the profit of the supply chain system, which is 256.6429 . When the per-unit wholesale price is 12.1707 , the farmer obtains the total profit of the supply chain system. Therefore, a reasonable wholesale price is in the interval of $(7.2410,12.1707)$.

Table II: Benchmark analysis.

\begin{tabular}{|c|c|c|c|c|c|c|}
\hline$q_{C}^{*}$ & $Q_{C}^{*}$ & $\theta^{*}$ & $\Theta^{*}$ & $w_{L}$ & $w_{U}$ & $\Pi_{C}^{*}$ \\
\hline 71.0630 & 75.3937 & 0.6905 & 0.7585 & 7.2410 & 12.1707 & 256.6429 \\
\hline
\end{tabular}

The sensitivity analysis of the changes in $\sigma_{X}, \sigma_{U}$ and $\sigma_{O}$ on the parameters shown in Table II is discussed below.

\subsection{Sensitivity analysis for demand risk}

Assume that $\sigma_{X}$ changes in the range from 3 to 7 , namely, the standard deviation of the random demand fluctuates within $40 \%$ of the standard reference variance $\sigma_{X}=5$. The assignment of the other parameters is the same as that in Section 3.1. The corresponding results of each optimal decision are shown in Fig. 2. Meanwhile, the relevant optimal decisions are calculated when $\sigma_{X}$ changes from 3 to 7 with one step length, as shown in Table III.

With the gradual increase of the standard deviation of the demand, Fig. 2 a shows that the planned ordering quantity $q_{C}^{*}$ of the enterprise also gradually increases by $3.66 \%$, while the planned planting quantity $Q_{C}^{*}$ of the farmer decreases by $1.81 \%$. Fig. $2 \mathrm{~b}$ shows that the optimal expected profit $\Pi_{C}^{*}$ of the whole FSC reduces by $3.76 \%$ due to the increase in the standard deviation of the demand. Fig. $2 \mathrm{c}$ shows that the ratio of the expected order quantity of the enterprise to the planned planting quantity of the farmer $\theta^{*}$ increases with the increase in the variance, and the rate of the expected sales volume of the product and the expected order quantity $\Theta^{*}$ decreases with an increase in the variance. This result shows that as market risk increases, the amount of wolfberry ordered by the enterprise is closer to the planned output of wolfberry, but the sales volume decreases due to the risk. Fig. $2 \mathrm{~d}$ shows the changing trend of the critical values of the wholesale price parameters when the enterprise and the farmer obtain the optimal profit of the supply chain; the profits of the enterprise and farmer decrease with the risk increasing. This result shows that as the risk increases, the enterprise (farmer) can capture the optimal profit of the supply chain system by setting (demanding) a relatively low wholesale price. The above data can be calculated from the results shown in Table III.

As shown in Table III, as the demand risk increases, the gap between the planned planting amount of the farmer and the planned ordering amount of the enterprise gradually reduces from $8.73 \%$ to $2.99 \%$, and the satisfaction rate of the expected ordering amount of the enterprise reduces from $74.66 \%$ to $71.31 \%$. At the same time, the expected sales volume of the enterprise decreases from 39.8794 to 38.9652 , a decrease of $2.29 \%$. In addition, the price negotiation space in which the farmer and enterprise can share the optimal profit of the supply chain shifts from the range of $(7.2824,12.2873)$ to the field of $(7.2215,12.0862)$ due to the increase in risk. 

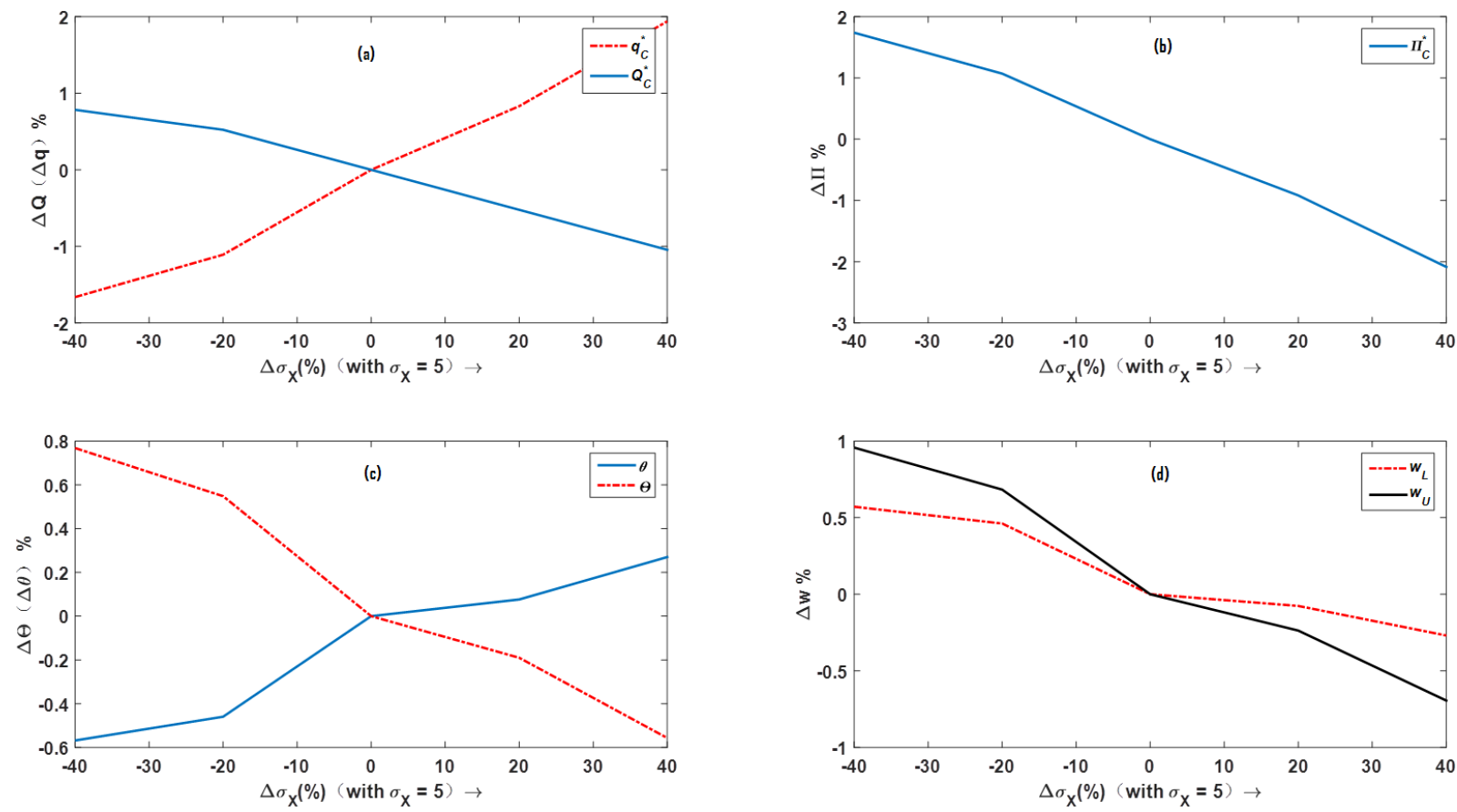

Figure 2: Sensitivity analysis (reference variance, $\sigma_{X}=5$ with variation range $\pm 40 \%$ ).

Table III: Sensitivity analysis $\left(\sigma_{X} \in[3,7]\right.$ with one step length).

\begin{tabular}{|c|c|c|c|c|c|c|c|}
\hline$\sigma_{X}$ & $q_{C}^{*}$ & $Q_{C}^{*}$ & $\theta^{*}$ & $\Theta^{*}$ & $w_{L}$ & $w_{U}$ & $\Pi_{C}^{*}$ \\
\hline 3.0000 & 69.8819 & 75.9843 & 0.6866 & 0.7644 & 7.2824 & 12.2873 & 261.1044 \\
\hline 4.0000 & 70.2756 & 75.7874 & 0.6873 & 0.7627 & 7.2744 & 12.2539 & 259.3877 \\
\hline 5.0000 & 71.0630 & 75.3937 & 0.6905 & 0.7585 & 7.2410 & 12.1707 & 256.6429 \\
\hline 6.0000 & 71.6535 & 75.0000 & 0.6910 & 0.7571 & 7.2355 & 12.1419 & 254.2873 \\
\hline 7.0000 & 72.4409 & 74.6063 & 0.6924 & 0.7543 & 7.2215 & 12.0862 & 251.2912 \\
\hline
\end{tabular}

\subsection{Sensitivity analysis for output risk}

Assume that $\sigma_{U}$ changes in the range from 0.16 to 0.24 , the standard deviation of wolfberry output is within $20 \%$ of the standard reference deviation of $\sigma_{U}=0.2$. And the values of the other parameters are the same as those in Section 3.1. The corresponding results for each optimal decision are shown in Fig. 3. Meanwhile, we set the step length as 0.02 to calculate the optimal choices when $\sigma_{U}$ changes from 0.16 to 0.24 . The results are shown in Table IV.

Fig. 3 a shows that the enterprise's planned order quantity $q_{C}^{*}$ is not affected by the output risk, but the farmer's planned planting quantity $Q_{C}^{*}$ decreases by $6.57 \%$ due to the increase in risk. Fig. $3 \mathrm{~b}$ shows that the optimal expected profit $\Pi_{C}^{*}$ of the supply chain system reduces by $9.84 \%$ as the output risk of wolfberry increases. Fig. $3 \mathrm{c}$ shows that both the ratio of the expected order quantity of the enterprise to the planned planting quantity of the farmer $\theta$ and the ratio of the expected sales volume of the product to the expected order quantity $\Theta$ decrease as the output risk increases. This result shows that both the expected order quantity of wolfberry and the expected sales volume of the products are reduced due to risk. Fig. $3 \mathrm{~d}$ shows the changing trend of the critical values of the wholesale price parameters when the enterprise and the farmer obtain the optimal profit of the supply chain. This figure shows that the per-unit wholesale price the enterprise needs to pay to capture the total profit of the supply chain increases as the output risk increases. The per-unit wholesale price the enterprise pays to obtain all the profit of the supply chain increases as the output risk increases, while the perunit wholesale price the farmer demands so it can receive all the profit of the supply chain 
decreases as the output risk increases. The above data can be calculated from the results shown in Table IV.

As shown in Table IV, as the output risk increases, the error between the planned planting amount of the farmer and the planned ordering amount of the enterprise gradually decreases from $9.70 \%$ to $2.49 \%$, and the satisfaction rate of the expected ordering amount of the enterprise also decreases from $74.06 \%$ to $70.34 \%$. At the same time, the expected sales volume of the enterprise decreases from 41.1113 to 37.8997 , which is a decrease of $7.81 \%$. In addition, the price negotiation space in which the farmer and the enterprise can share the optimal profit of the supply chain changes from the range of $(7.2125,12.2167)$ to the range of $(7.2856,12.1636)$ due to the increase in risk.
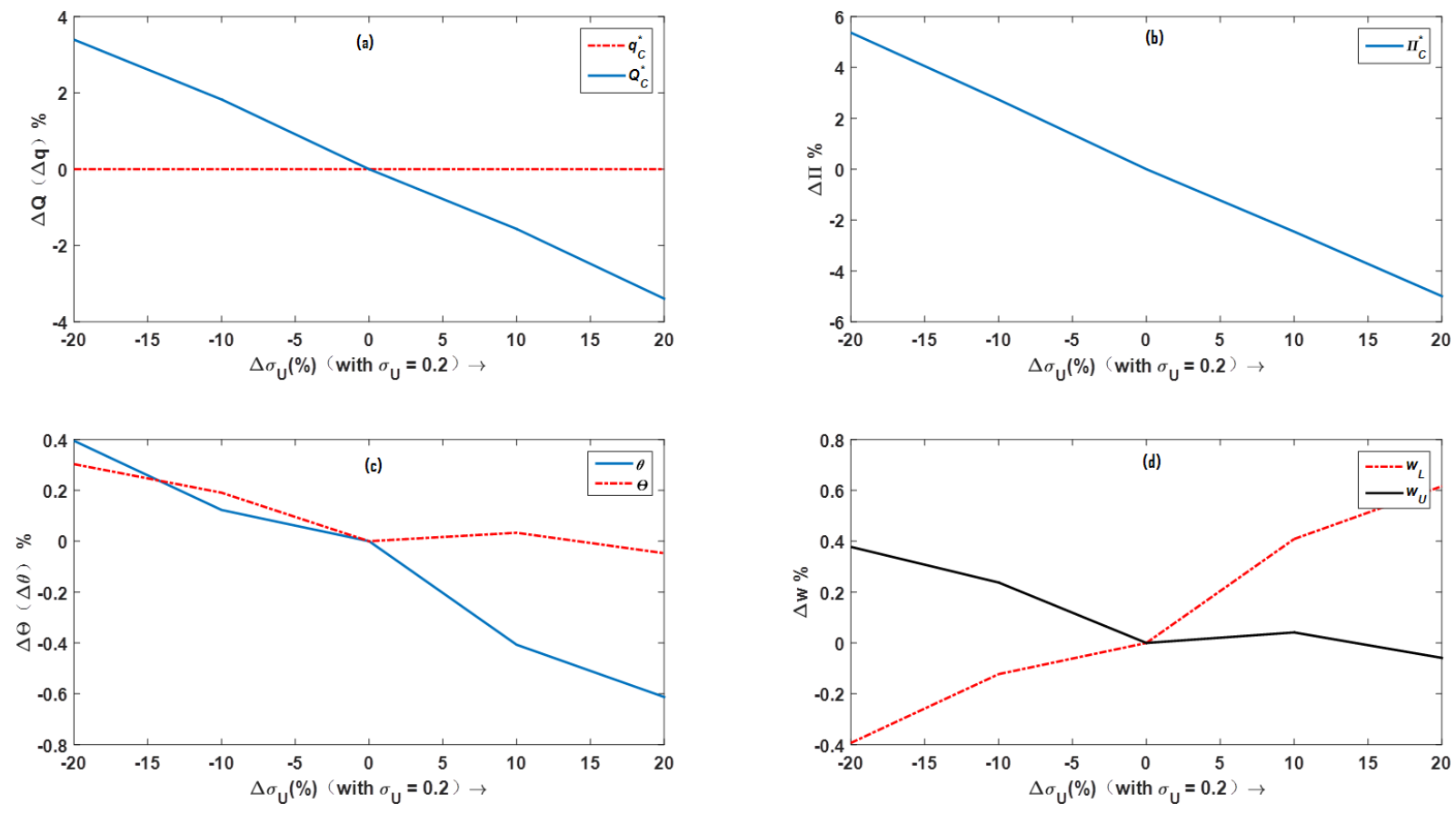

Figure 3: Sensitivity analysis (reference variance, $\sigma_{U}=0.2$ with variation range $\pm 20 \%$ ).

Table IV: Sensitivity analysis $\left(\sigma_{U} \in[0.16,0.24]\right.$ with step length is equalled to 0.02$)$.

\begin{tabular}{|c|c|c|c|c|c|c|c|}
\hline$\sigma_{U}$ & $q_{C}^{*}$ & $Q_{C}^{*}$ & $\theta^{*}$ & $\Theta^{*}$ & $w_{L}$ & $w_{U}$ & $\Pi_{C}^{*}$ \\
\hline 0.1600 & 71.0630 & 77.9528 & 0.6932 & 0.7608 & 7.2125 & 12.2167 & 270.4253 \\
\hline 0.1800 & 71.0630 & 76.7717 & 0.6914 & 0.7600 & 7.2321 & 12.1996 & 263.6617 \\
\hline 0.2000 & 71.0630 & 75.3937 & 0.6905 & 0.7585 & 7.2410 & 12.1707 & 256.6429 \\
\hline 0.2200 & 71.0630 & 74.2126 & 0.6877 & 0.7588 & 7.2706 & 12.1757 & 250.3412 \\
\hline 0.2400 & 71.0630 & 72.8346 & 0.6863 & 0.7582 & 7.2856 & 12.1636 & 243.8250 \\
\hline
\end{tabular}

\subsection{Sensitivity analysis for processing risk}

Assume that $\sigma_{O}$ changes in the range from 0.08 to 0.12 ; that is, the standard deviation of wolfberry circulation loss risk fluctuates within $20 \%$ of the standard reference deviation of $\sigma_{O}=0.1$. And the assignment of the other parameters is the same as that in Section 3.1. The corresponding results of each optimal decision are shown in Fig. 4; meanwhile, the step length is set as 0.02 , and the relevant optimal decisions are determined when $\sigma_{O}$ changes from 0.16 to 0.24 . The results are shown in Table V.

Fig. 4 a shows that the planned order quantity of the enterprise $q_{C}^{*}$ increases by $2.53 \%$ as the processing risk increases, and the planned planting quantity of the farmer $Q_{C}^{*}$ decreases by $1.81 \%$ as the processing risk increases. Fig. $4 \mathrm{~b}$ shows that the optimal expected profit $\Pi_{C}^{*}$ of 
the supply chain system decreases by $3.21 \%$ with the increase in the wolfberry output risk. Fig. $4 \mathrm{c}$ shows that the ratio of the expected order quantity of the enterprise to the planned planting quantity of the farmer $\theta^{*}$ increases with the increase in the processing risk, and the proportion of the expected sales volume of the products to the expected order quantity $\Theta^{*}$ decreases with the increase in the processing risk. This result shows that due to the increase in the processing risk, the expected amount of wolfberry is closer to the planned planting amount, but the expected sales volume of the products is reduced due to the risk. Fig. $4 \mathrm{~d}$ shows the changing trend of the critical values of the wholesale price parameters when the enterprise and the farmer obtain the optimal profit of the supply chain. The figure shows that the per-unit wholesale price paid (demanded) by the enterprise (the farmer) to capture the total profit of the supply chain decreases as the processing risk increases. The above data can be calculated from the results shown in Table $\mathrm{V}$.

As shown in Table $\mathrm{V}$, due to the increase in the processing risk, the gap between the planned planting amount of the farmer and the planned ordering amount of the enterprise gradually decreases from $8.71 \%$ to $4.11 \%$, and the satisfaction rate of the expected ordering amount of the enterprise also decreases from $74.66 \%$ to $72.11 \%$. At the same time, the expected sales volume of the enterprise decreases by $2.11 \%$ from 39.9263 to 39.0844 . In addition, the price negotiation space in which the farmer and the enterprise can share the optimal profit of the supply chain is moved from the range of $(7.2802,12.2618)$ to the range of $(7.2188,12.0876)$ due to the increase in the processing risk.
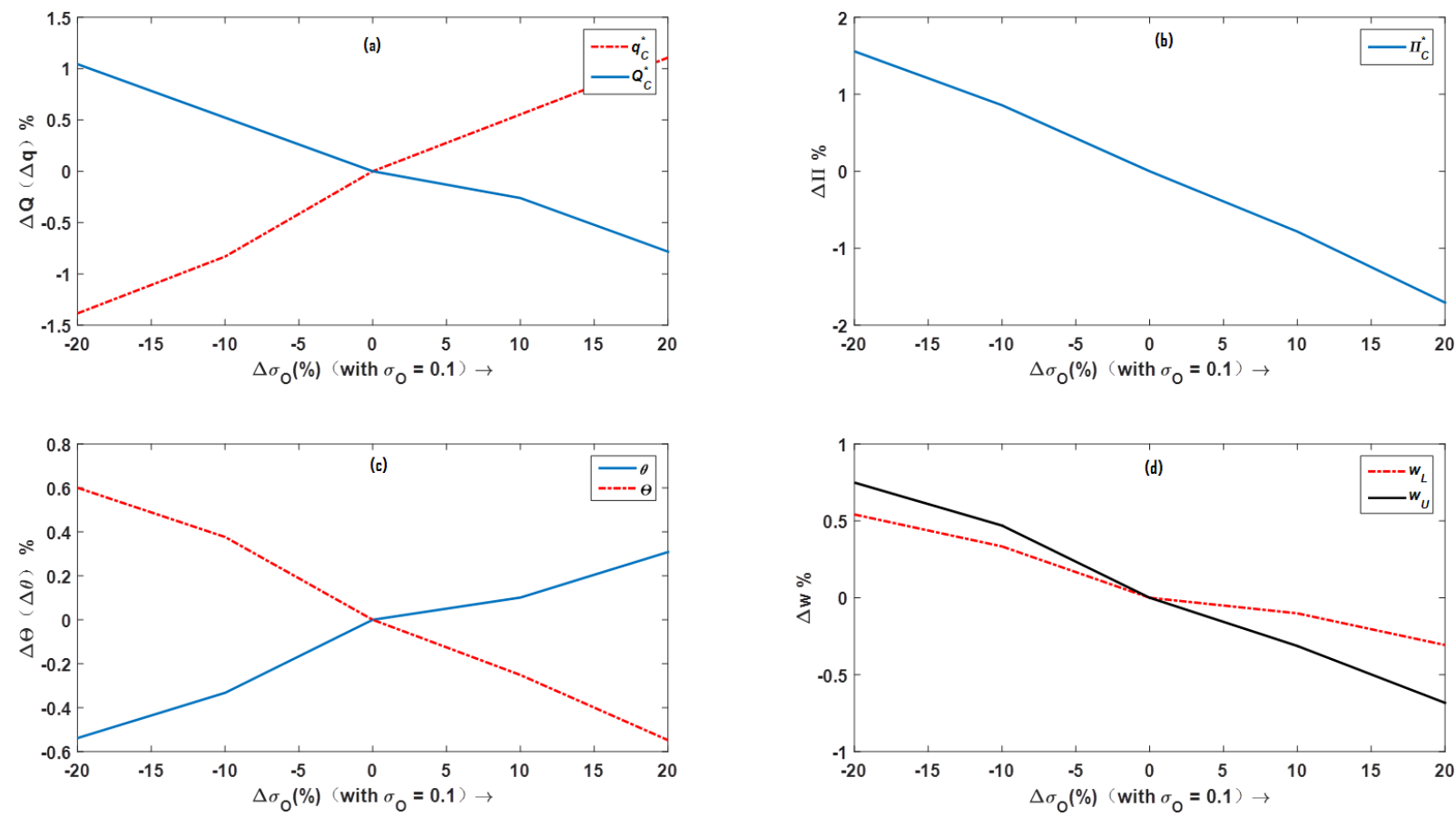

Figure 3: Sensitivity analysis (reference variance, $\sigma_{O}=0.1$ with variation range $\pm 20 \%$ ).

Table V: Sensitivity analysis ( $\sigma_{O} \in[0.08,0.12]$ with step length is equalled as 0.02$)$.

\begin{tabular}{|c|c|c|c|c|c|c|c|}
\hline$\sigma_{O}$ & $q_{C}^{*}$ & $Q_{C}^{*}$ & $\theta^{*}$ & $\Theta^{*}$ & $w_{L}$ & $w_{U}$ & $\Pi_{C}^{*}$ \\
\hline 0.0800 & 70.0787 & 76.1811 & 0.6868 & 0.7631 & 7.2802 & 12.2618 & 260.6425 \\
\hline 0.0900 & 70.4724 & 75.7874 & 0.6882 & 0.7614 & 7.2651 & 12.2278 & 258.8450 \\
\hline 0.1000 & 71.0630 & 75.3937 & 0.6905 & 0.7585 & 7.2410 & 12.1707 & 256.6429 \\
\hline 0.1100 & 71.4567 & 75.1969 & 0.6912 & 0.7566 & 7.2337 & 12.1326 & 254.6318 \\
\hline 0.1200 & 71.8504 & 74.8031 & 0.6926 & 0.7544 & 7.2188 & 12.0876 & 252.2644 \\
\hline
\end{tabular}




\section{CONCLUSION}

This paper considers a two-echelon fresh-product supply chain and investigates the optimal solutions and risk-sharing decisions of participants when the output, circulation and market demand are all uncertainties. The main contributions of this paper can be summarized as follows:

First, there is a unique optimal decision that will maximize the expected profit of the global FSC; that is, both the optimal order quantity of the enterprise and the optimum planting quantity of the farmer exist, and they are unique. Second, a wholesale price contract with random output, circulation and demand risks can coordinate the fresh produce supply chain, and the enterprise and farmer can distribute the optimal expected profit of the system and share these random risks. Finally, according to the results of the simulation and the sensitivity analysis, the optimal order quantity of the enterprise increases as the demand risk and processing risk increase but remains unchanged as the output risk increases. As long as the random risk increases, the optimal planting quantity of the fresh products and the optimal profit of the system will decrease.

Future studies will consider the following question: How can the circulation risk be reduced or the circulation risk transferred to the third-party logistics provider through freshkeeping technology? When considering the price as an endogenous variable and the loss of fresh products during circulation and in the market, how will the optimal decision making of the enterprise, the farmer and supply chain be affected? When the enterprise, the farmer or both are faced with unsystematic risk and have a particular risk propensity, how will the risk affect the supply chain management strategies? These are future research directions considered by the research group.

\section{ACKNOWLEDGEMENT}

This work is supported by the Humanities and Social Sciences Research Project of the Ministry of Education of China (with grant number 18YJC630030, 16YJAZH012), the National Social Science Foundation Key Project of China (with grant number 17AGL007), the financial support of the CSC (with grant number 201908505102), the Youth Project of Chongqing Technology and Business University (with grant number 1951026), and Innovative Research Project for Graduate Students of Chongqing Technology and Business University (with grant number yjscxx2019-101-91).

\section{REFERENCES}

[1] Mohammadi, H.; Ghazanfari, M.; Pishvaee, M. S.; Teimoury, E. (2019). Fresh-product supply chain coordination and waste reduction using a revenue-and-preservation-technology-investmentsharing contract: a real-life case study, Journal of Cleaner Production, Vol, 213, 262-282, doi:10.1016/j.jclepro.2018.12.120

[2] Rasi, R. E.; Hatami, D. (2019). Environmental risk and innovation in supply chain: analysis of influence of supply chain agility, Journal of System and Management Science, Vol. 9, No. 3, 125

[3] Shukla, M.; Jharkharia, S. (2013). Agri-fresh produce supply chain management: a state-of-theart literature review, International Journal of Operations \& Production Management, Vol. 33, No. 2, 114-158, doi: $10.1108 / 01443571311295608$

[4] Mena, C.; Terry, L. A.; Williams, A.; Ellram, L. (2014). Causes of waste across multi-tier supply networks: cases in the UK food sector, International Journal of Production Economics, Vol. 152, 144-158, doi:10.1016/j.ijpe.2014.03.012

[5] Monier, V.; Shailendra, M.; Escalon, V.; O'Connor, C.; Gibon, T.; Anderson, G.; Montoux, H.; Reisinger, H.; Dolley, P.; Ogilvie, S.; Morton, G. (2010). Preparatory study on food waste across EU 27, Technical Report - 2010 - 054, European communities, European Commision (DG Environment), Brussels 
[6] Hsu, P. H.; Wee, H. M.; Teng, H. M. (2010). Preservation technology investment for deteriorating inventory, International Journal of Production Economics, Vol. 124, No. 2, 388394, doi:10.1016/j.ijpe.2009.11.034

[7] Dye, C.-Y.; Hsieh, T.-P. (2012). An optimal replenishment policy for deteriorating items with effective investment in preservation technology, European Journal of Operational Research, Vol. 218, No. 1, 106-112, doi:10.1016/j.ejor.2011.10.016

[8] Lee, Y.-P.; Dye, C.-Y. (2012). An inventory model for deteriorating items under stock-dependent demand and controllable deterioration rate, Computers \& Industrial Engineering, Vol. 63, No. 2, 474-482, doi:10.1016/j.cie.2012.04.006

[9] Dye, C.-Y. (2013). The effect of preservation technology investment on a non-instantaneous deteriorating inventory model, Omega, Vol. 41, No. 5, 872-880, doi:10.1016/ j.omega.2012.11.002

[10] Guarnieri, P.; Sobreiro, V. A.; Nagano, M. S.; Serrano, A. L. M. (2015). The challenge of selecting and evaluating third-party reverse logistics providers in a multi-criteria perspective: a Brazilian case, Journal of Cleaner Production, Vol. 96, 209-219, doi:10.1016/ j.jclepro.2014.05.040

[11] Dye, C.-Y.; Yang, C.-T. (2016). Optimal dynamic pricing and preservation technology investment for deteriorating products with reference price effects, Omega, Vol. 62, 52-67, doi:10.1016/j.omega.2015.08.009

[12] Burinskiene, A.; Lorenc, A.; Lerher, T. (2018). A simulation study for the sustainability and reduction of waste in warehouse logistics, International Journal of Simulation Modelling, Vol. 17, No. 3, 485-497, doi:10.2507/IJSIMM17(3)446

[13] Xiao, Y.-B.; Chen, J.; Xu, X.-L. (2008). Fresh product supply chain coordination under CIF business model with long distance transportation, Systems Engineering - Theory \& Practice, Vol. 28, No. 2, 19-34, doi:10.1016/S1874-8651(09)60009-0

[14] Govindan, K.; Popiuc, M. N.; Diabat, A. (2013). Overview of coordination contracts within forward and reverse supply chains, Journal of Cleaner Production, Vol. 47, 319-334, doi: $10.1016 /$ j.jclepro.2013.02.001

[15] Li, Z. P.; Zhang, J. L.; Zhang, H. J.; Hua, G. W. (2017). Optimal selection of movable shelves under cargo-to-person picking mode, International Journal of Simulation Modelling, Vol. 16, No. 1, 145-156, doi:10.2507/IJSIMM16(1)CO2

[16] Papargyropoulou, E.; Lozano, R.; Steinberger, J. K.; Wright, N.; bin Ujang, Z. (2014). The food waste hierarchy as a framework for the management of food surplus and food waste, Journal of Cleaner Production, Vol. 76, 106-115, doi:10.1016/j.jclepro.2014.04.020

[17] Su, J.; Wu, J.; Liu, C. (2014). Research on coordination of fresh produce supply chain in big market sales environment, The Scientific World Journal, Vol. 2014, Paper 873980, 12 pages, doi: $10.1155 / 2014 / 873980$

[18] Wang, C.; Chen, X. (2017). Option pricing and coordination in the fresh produce supply chain with portfolio contracts, Annals of Operations Research, Vol. 248, No. 1-2, 471-491, doi: $10.1007 / \mathrm{s} 10479-016-2167-7$

[19] Fang, X. (2018). Analysis of double marginalization effect on the wholesale price contract coordination, Asia-Pacific Journal of Operational Research, Vol. 35, No. 2, Paper 1840005, 15 pages, doi:10.1142/S0217595918400055

[20] Moon, S.; Ji, W.; Moon, H.; Kim, D. (2018). A simulation of order resonance phenomenon in a supply chain triggered by reinforcing loop, International Journal of Simulation Modelling, Vol. 17, No. 2, 231-244, doi:10.2507/IJSIMM17(2)421

[21] Pal, H.; Bardhan, S.; Giri, B. C. (2018). Optimal replenishment policy for non-instantaneously perishable items with preservation technology and random deterioration start time, International Journal of Management Science and Engineering Management, Vol. 13, No. 3, 188-199, doi: $10.1080 / 17509653.2017 .1372228$

[22] Li, G.; He, X.; Zhou, J.; Wu, H. (2019). Pricing, replenishment and preservation technology investment decisions for non-instantaneous deteriorating items, Omega, Vol. 84, 114-126, doi:10.1016/j.omega.2018.05.001

[23] Gokarn, S.; Kuthambalayan, T. S. (2019). Creating sustainable fresh produce supply chains by managing uncertainties, Journal of Cleaner Production, Vol. 207, 908-919, doi:10.1016/ j.jclepro.2018.10.072 